\title{
Various Methods, Procedures and Tools for Improvement of Quality and Standards in Medical Sciences and Neurosciences
}

\author{
PK Upadhyay ${ }^{1 *}$, G Tiwary ${ }^{2}$, K Upadhyay ${ }^{3}$ and U Kartikeya ${ }^{3}$ \\ ${ }^{1}$ Head of Neurosurgery and Associate Professor and Communicating Author, India \\ ${ }^{2}$ Director of Diagnostic Services, India \\ ${ }^{3} \mathrm{MBBS}$ Fellows, India \\ *Corresponding Author: PK Upadhyay, Head of Neurosurgery and Associate \\ Professor and Communicating Author, India.
}

Received: May 28, 2021

Published: July 08, 2021

(C) All rights are reserved by PK Upadhyay., et al.

\begin{abstract}
Quality in medical sciences and neurosciences is demand of the day. Any visiting patient want the assurance of good quality and standards of service before vouching for the service. Quality and standards are continuous processes. One has to learn from past deficiencies which is founds on different medical audits and then device new system or methods or processes to overcome the deficiency. Various methods to keep abreast the continued improvement in quality is described.

Keywords: QualityTools; Quality Improvement, Quality Standards; Flow Charts; Cause and Effect Diagram (Fish Bone/Ishikawa Charts); Parito-charts (80:20 charts); Check-sheet; Control Charts; Histogram; Scattered Diagram; Brain Storming
\end{abstract}

\section{Introduction}

Various methods, process, procedures and Tools of quality improvement

Various Processes is required in earlier stage to access achievement of various audits $[1,2]$.

In the earliest stage of quality improvement several steps are taken. Using a number of different quality tools for assessment. Eight such quality tools can be used to find better identify and improve their processes in a organization or institutions $[3,4]$. These tools for the finding or identify and improve the quality are.

Eight quality tools:

- Use of Flow charts.

- Cause and effect diagram (Fish bone/Ishikawa charts).

- $\quad$ Parito- charts (80:20 charts).
- $\quad$ Check- sheet.

- Control charts.

- Histogram.

- Scattered diagram.

- Brain Storming.

After world war two Japanese adopted 'quality' as the philosophy for economic recovery $[5,6]$. They sought seven tools to accomplish the economic recovery $[7,8]$.

Each one ids described in detail now.

Flow chart

Flow chart gives visual illustration of the sequence of the operations needed to complete task. Every process is put to, till finish the job. 


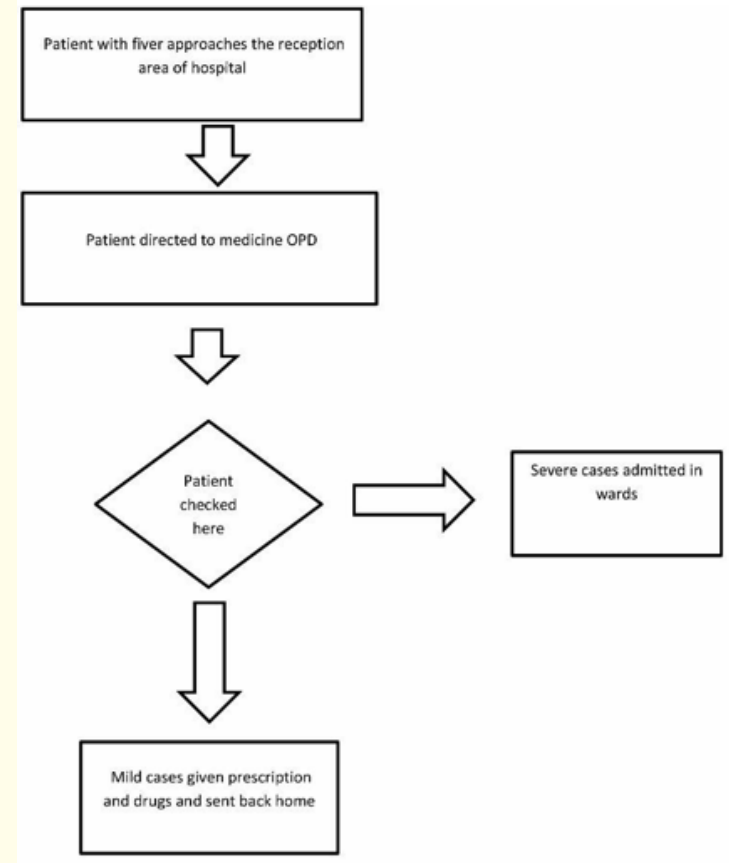

Diagram showing Flow-Chart

Figure 1

Cause and effect diagram (Fish bone/Ishikawa charts)

- Cause and effect diagram also known as fishbone diagram helps to obtain more information about process and its output. It will help to find out root cause.

- In 1943 Kaoru Ishikawa developed the cause and effect diagram at the University of Tokyo.

- This diagram has two sides on right side is the list of effect which lists the problem or the quality concern. On left side is the cause side, it list the primary cause of the problems.

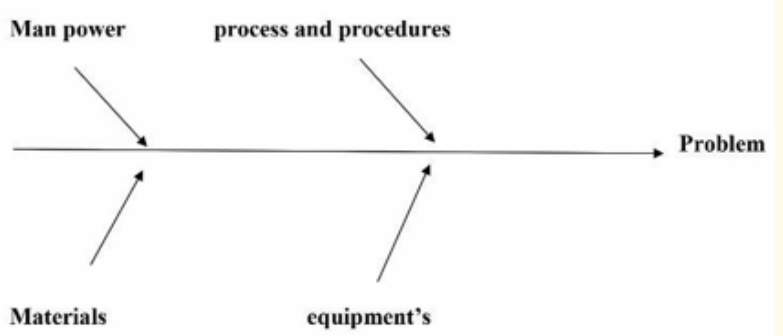

Figure 2: Ishikawa/Fish bone diagram/cause and effect diagram.
Parito-charts (80:20 charts)

- $\quad$ Parieto charts is used to priorities the problems (P for P), to decide what problems should be addressed.

- It was devised by Vilfred Parieto in1906 in Italy.

- No organization will have enough resource to handle every problem so they should priorities them. That is the "important few and trivial many".

- So, to priorities the problem finds out its causes and try to correct them first and then proceed on.

Check-sheet

Check sheet will allow user to collect data directly from process and put them as tables which makes it easy, systematic and organized manner which shows the history and pattern of variation.

At the beginning, in change of process, this tool is used to recognize the problems and collect the data easily.

There could be:

- Defective item check sheet.

- Defective location check sheet.

- Defective cause check sheet.

- Check-up confirmation check sheet.

Control charts

- The Control charts was developed in mid-1920 by Walter Shewhart of Bell Labs.

- Control charts are used to make sure that the process is in control.

- It is also used to monitor and control the process variations on a continuous basis.it also allows the user to take proper corrective actions to eliminate the sources of variations.

- This tool has become a main contributor to the quality improvement process.

\section{Histogram}

Histogram is the tool used for summarizing analyzing and displaying the data. It gives the user a graphical representation of the amount of variation found in the set of data. Histogram shows a visual summary of data, which will be simple to understand. This tool is used when the data given is of various verities and is difficult to understand. 
Histogram could be of five types:

- $\quad$ Bell shaped.

- Double peak type.

- Plateau distribution.

- $\quad$ Comb type distribution.

- $\quad$ Skewed Distribution.

\section{Scattered diagram}

Scattered diagram is used to recognize the correlation which might exist between the quality characteristic and the factor which might be driving it. A scattered diagram is the nonmathematical or graphical approach for recognizing relationship between the performance measure and the factors which might be driving it. The scattered diagram is used when there is assumed variation of two item, connected in some way.

\section{Brain storming}

In this connected people with process, discuss together, the pros and cons and finally reach a conclusion and solution to the problem. Finally, brain storming is done with all stakeholder to find out reasons of problem and various ways to deal the problems and thereby improve quality of service.

\section{Results}

These services were found efficient way of improving the standards and quality of services provided by the institutions.

\section{Discussion}

Using medical audits we find the deficiency in the service or the process.

Now these methods are used to find the cause of fault or deficiency. One the deficiency is identified the same is corrected and again tested for results till it gives correct result of service to the satisfaction of patient, organisations or institutions [9].

\section{Conclusion}

These tools are efficient at improving the quality of service by the institutions and there by satisfying the clients and the patients.

\section{Declaration}

No financial help has been taken from any financial institutions, companies. There is no conflict of interests.

\section{Bibliography}

1. Upadhyay PK and Tiwary G. "Concept of Quality services in Medical Science with special assurance to Super specialty surgical practice". Medical Science 11.41 (2014): 24-30.

2. Tiwary G and Upadhyay PK. "Safe conduct of medical or surgical procedures including neurosurgical procedures and special operating procedures (SOP)". Medical Science 11.41 (2014): 31-36.

3. Upadhyay PK and Tiwary G. "Standard of operation theatres (OT)/Procedural rooms”. Medical Science 1.41 (2014): 37-42.

4. P K Upadhyay., et al. "Quality assurance in neurosciences and suitable standards for Neurosurgical operation theatre and procedural rooms". 1.1 (2018): 180002.

5. PK Upadhyay., et al. "Text Book of Quality assurance and Standards in Neuro and medical sciences". Smash world, USA (2019).

6. P K Upadhyay. "Text book of quality assurance and standards in Neurosurgery and surgical sciences". (2020).

7. PK Upadhyay., et al. "Text Book of Quality assurance and Standards in Neuro and medical sciences". Dr P.K. Upadhyay, Tiwary G, Kritika, Kartikeya; Smash world, USA, 2nd edition (2020).

8. Upadhyay PK., et al. "Quality Medical Service for Quality Assurance in Neurosciences and Medical Sciences Using International Standard Organization, Quality Standards and Concepts of Total Quality management (TQM)". Acta Scientific Medical Sciences 4.12 (2020).

9. Upadhyay PK., et al. "Methods to provide quality assurance in Medical Science and Neuroscience using International Standard Organization, Quality Standards and concepts of Total Quality management (TQM)". 3.1 (2020): 180017.

\section{Volume 5 Issue 8 August 2021}

(C) All rights are reserved by PK Upadhyay., et al. 